\title{
Comparative Efficacy of Different Inactivated Hydro-Pericardium Syndrome Vaccines Prepared from Infected Liver and Vero Cell Line Adapted Adeno Type 4 Virus
}

\author{
Muhammad Danish Mehmood1*, Huma Anwarul-Haq1, Faisal Amin², Sajjad Hussain ${ }^{3}$, \\ Ejaz Rafique ${ }^{4}$, Muhammad Usman Ghani' ${ }^{1}$, Muhammad Ismail ${ }^{1}$, Fareeha Ghaffar ${ }^{4}$ \\ ${ }^{1}$ Ottoman Pharma (Immuno Division), Lahore, Pakistan \\ ${ }^{2}$ Grandparent Diagnostic Laboratory, Lahore, Pakistan \\ ${ }^{3}$ Veterinary Research Institute, Lahore, Pakistan \\ ${ }^{4}$ Institute of Molecular Biology and Biotechnology, University of Lahore, Lahore, Pakistan \\ Email: ^drdanishmehmood@gmail.com, farihaach54@gmail.com,Huma.anwar16@gmail.com, \\ sajjadsanghi@gmail.com,Ejazrafique90@gmail.com
}

How to cite this paper: Mehmood, M.D., Anwarul-Haq, H., Amin, F., Hussain, S., Rafique, E., Ghani, M.U., Ismail, M. and Ghaffar, F. (2020) Comparative Efficacy of Different Inactivated Hydro-Pericardium Syndrome Vaccines Prepared from Infected Liver and Vero Cell Line Adapted Adeno Type 4 Virus. World Journal of Vaccines, 10, 1-16.

https://doi.org/10.4236/wjv.2020.101001

Received: October 21, 2019

Accepted: December 22, 2019

Published: December 25, 2019

Copyright () 2020 by author(s) and Scientific Research Publishing Inc. This work is licensed under the Creative Commons Attribution International License (CC BY 4.0).

http://creativecommons.org/licenses/by/4.0/

(c) (i) Open Access

\begin{abstract}
Hydro-Pericardium Syndrome (HPS) is viral problem of commercial poultry caused by aviadeno virus type- 4 . In Pakistan the problems have been controlled by administering inactivated infected liver homogenate vaccine (ILHV). The use of liver based HPS vaccines remained potential threat for having hypersensitivity reactions in poultry. The current study was carried out to compare the serological potency of HPS ILHV to vero cell line adopted vaccine in term of anti HPS-ELISA antibody titers. 14 HPS virus vaccines were prepared based on different concentration of antigen, type of adjuvants and source of virus substrate. Total of 160 birds were divided into 16 groups each containing 10 birds. At day of $14^{\text {th }}$ age each bird of every group was injected with $0.3 \mathrm{ml}$ dose of respective vaccine. It was observed that HPS infected liver based vaccine having $1 \times 10^{5.6}, 1 \times 10^{5.6}$ and $1 \times 10^{3.6}$ bird lethal dose 50 induced 1092.10, 875.25 and 702.2 anti-HPS ELISA antibody titer respectively. The 20, 25 and 30 doses/gm HPS infected liver vaccine induced 110.4, 1071.9 and 1037.8 anti-HPS ELISA antibody titer respectively. Montanide based tissue culture HPS vaccine showed significantly higher 1148.45 anti-HPS ELISA antibody titer to aluminium hydroxide based vaccine (137.2) $(\mathrm{P}<0.05)$. It is concluded that montanide based HPS vaccine prepared from tissue culture technique having biological titer $\geq 1 \times 10^{5.6} \mathrm{TCID}_{50}$ is serological potent against field infection. The vaccines based on such formulation could be prepared in future for effective immuno-prophylaxis against HPS virus.
\end{abstract}




\section{Keywords}

Hydro-Pericardium Syndrome, Vero Cell Line, Infected Liver Homogenate, Cytopathic Effect, Tissue Culture Infective Dose, Montanide, HPS ELISA

\section{Introduction}

Hydro-pericardium syndrome (HPS) associated hepatitis is a viral illness of poultry especially 3 to 6 week old chicks caused by fowl adenovirus serotype-4. It was first reported in 1987 at Angara Goth near Karachi, Pakistan. Poultry industry is considered to be a most effective growing industry in the commercial sector due to increasing demand of its value added products. Although, the industry in Pakistan is highly organized and well established but still it suffers from highly infectious outbreaks of Hydro-pericardium Syndrome, Infectious Avian Bronchitis, Newcastle Disease, Infectious Bursal Disease and Chronic Respiratory Disease. The HPS has made massive economic losses in past to the Pakistan poultry industry [1] [2] [3].

The serotype 4 of fowl adenovirus belongs to family adenoviridae genus aviadenovirus. The virus is non-enveloped, $70-90 \mathrm{~nm}$ size, icosahedral particles with linear, double standard DNA genome. The antigen of fowl adenovirus was isolated from geese, ducks and turkeys [4]. The disease is characterized by impulsive onset desolation, mortality upto $70 \%$, and accumulation of straw color fluid in the pericardial sac, liver is marked with necrotic foci, and intra-nuclear inclusion bodies in hepatocytes are the cardinal lesion observed during postmortem [5] [6]. The pericardial fat may exhibit yellowish discoloration with petechial hemorrhages and the heart appears misshapen and flabby at its apex floating in the pericardial sac.

Against most of the poultry diseases, standard vaccines are available but ample literature is still scanty regarding the standard protocols for development and evaluation of avian HPS virus vaccines from infected liver homogenate with and without different adjuvants. Single dose formalized liver homogenate vaccine prepared from infected HPS virus is develop to induce immunity in broilers against HPS and double dose of formalized liver homogenate is more efficacious in broilers [7]. So, extensive use of infected liver homogenate vaccine minimized production of cell culture based HPS vaccines [8]. Due to emerging viral resistance against various antiviral drugs, it becomes difficult to control viral problems that may result into heavy economic losses. Currently, there are few commercial vaccines available for immunophylaxis against HPS. All these vaccines are being manufactured in the country from local isolates by using conventional technique based on infected liver homogenate. In such scenario non-specific proteins such as (arginine, ornithine) of liver homogenate vaccine (HPS-ILHV) would have been showed allergic reactions after injection. Therefore, current study has been designed to develop standard protocols for production of cell free 
HPS vaccine in amalgamation with different adjuvants and to revise different quality control factors that mitigates in-vivo immune response in vaccinates.

\section{Material and Method}

\subsection{Source of HPS Virus}

200 gms of HPS virus infected liver was obtained from Ottoman Pharma, Lahore, Pakistan on the written request by director Institute of molecular biology and biotechnology (IMBB), The University of Lahore, Pakistan.

\subsection{Source and Rearing of Birds}

Total of 160-day old chicks were purchased from environmental controlled house of Big Bird Foods, Lahore, Pakistan. The chicks were shifted to properly clean and fumigated (17 gm $\mathrm{KMnO}_{4}+35 \mathrm{ml}$ formalin/100feet) environmental controlled experimental animal house, The University of Lahore, Punjab. These chicks were allocated in different cages according to the experimental design and offered with feed and water ad libitum.

\subsection{Reactivation of HPS Infected Liver}

40 percent weight/volume (W/V) infected liver homogenate was prepared by adding $40 \mathrm{gms}$ of infected liver in $100 \mathrm{ml}$ normal saline $(0.85 \%$ sodium chloride aqueous solution ( $\mathrm{pH}$ 7.2). The mixture was homogenized @ $1000 \mathrm{rpm}$ for 5 minutes using sharp blade electric homogenizer. The homogenate was centrifuged at $3000 \mathrm{rpm}$ for 10 minutes and sediment was decanted. The clear supernatant was admixed with gentamycin@ $200 \mu \mathrm{gms} / \mathrm{ml}$, penicillin @ 10,000 u/ml and streptomycin@ $100 \mu \mathrm{gms} / \mathrm{ml}$ [9].

26 days old 10 HPS susceptible chicks were given infection with one $\mathrm{ml}$ of the HPS infected liver homogenate inoculum through intramuscular route (IM). At postmortem morbid samples were educed and stored in sterile container having label "HPS infected liver". These HPS infected livers were stored at $-20^{\circ} \mathrm{C}$ till further processing.

\subsection{Calculation of $\mathrm{BLD}_{50}$}

Broilers of 26 days old (unvaccinated against HPS vaccine) were given infective dose for production of the disease. The dead birds were opened and HPS infected liver removed. The liver was homogenized in nine times volume of normal saline. Antibiotics such as gentamycin $200 \mu \mathrm{gms} / \mathrm{ml}$, penicillin $1000 \mathrm{u} / \mathrm{ml}$, streptomycin $1 \mathrm{mg} / \mathrm{ml}$ were added in the liver homogenate. The homogenate was diluted as 10-fold in the antibiotic containing normal saline (such as 1:1000, $1: 10,000,1: 100,000$, and 1:1,000,000). One $\mathrm{ml}$ of each dilution was injected to each of the 5 birds of the respective group.

The birds were marked with black dye and observed critically for mortality and morbidity for next 72 - 90 hrs for any mortality. Those birds died of HPS and showed fluid in the pericardium on post mortem examination were graded 
as infected. All the remaining birds were slaughtered and examined for signs of HPS. The $\mathrm{ALD}_{50}$ titer was calculated as the reciprocal of that dilution per unit volume of virus that killed $50 \%$ of bird's inoculated (Figure 1) [10].

\subsection{Preparation of Vaccine from HPSV Infected Liver Homogenate}

The liver homogenate with known units of infectivity titer $\left(\mathrm{LD}_{50}\right)$ was processed for preparation of vaccines as described by Rabbani (1987). Ten grams of the liver was homogenized in $35 \mathrm{ml}$ sterilized saline solution. $0.2 \%$ of $37 \%$ formaldehyde (Scharlau-UK), antibiotics (Streptomycin@1 mg/ml, penicillin @ 1000 units per $\mathrm{ml}$ and gentamycin @ $200 \mathrm{ug}$ per $\mathrm{ml}$ ) (Univet-Ireland) were added in the HPS infected liver homogenate. The suspension was incubated at $37^{\circ} \mathrm{C}$ for 24 hours and placed for overnight. The clear supernatant was decanted from the homogenate. The volume was made up to $45 \mathrm{ml}$ using the saline solution (Figure 2).

\subsection{Effect of Immunogen Dose}

\subsubsection{Effect of Dose (Vaccine Doses per Gram)}

Ten grams of HPS virus infected liver homogenate containing $1 \times 10^{5.6}$ units of the $\mathrm{LD}_{50}$ in $35 \mathrm{ml}$ of sterilized normal saline was processed for preparation of HPS vaccines. The volume was made up to $45 \mathrm{ml}$ using the saline solution. The resulting solution was having immunogen amount 3 doses per gram. The 3 doses per gram vaccine was further diluted to make a volume $6 \mathrm{ml}, 7.5 \mathrm{ml}$ and $9 \mathrm{ml}$
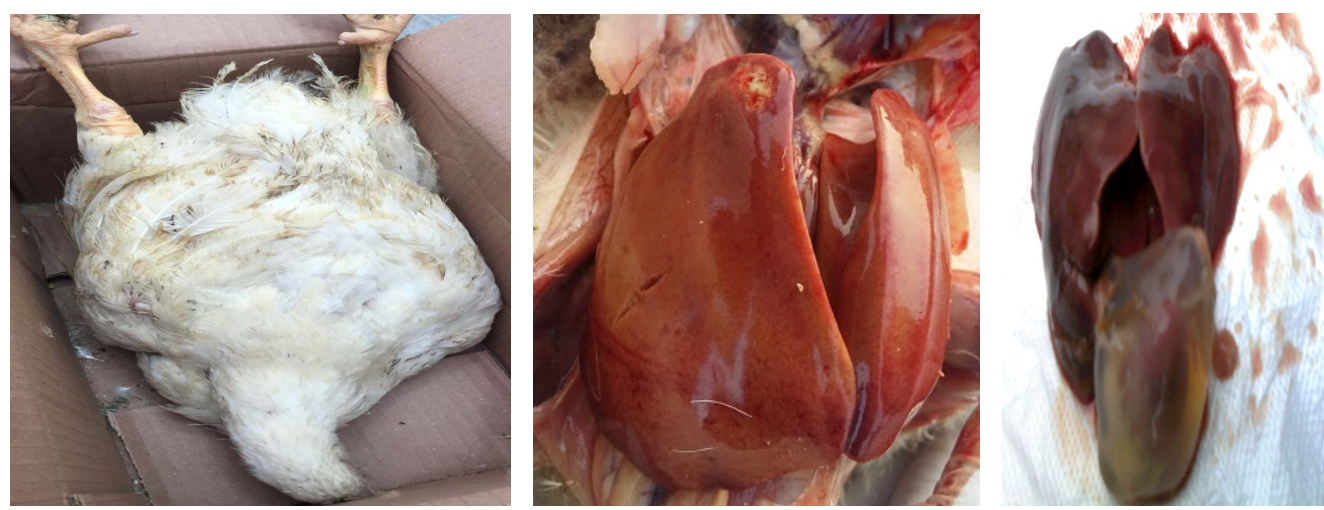

Figure 1. Pathognomonic lesions of HPS.

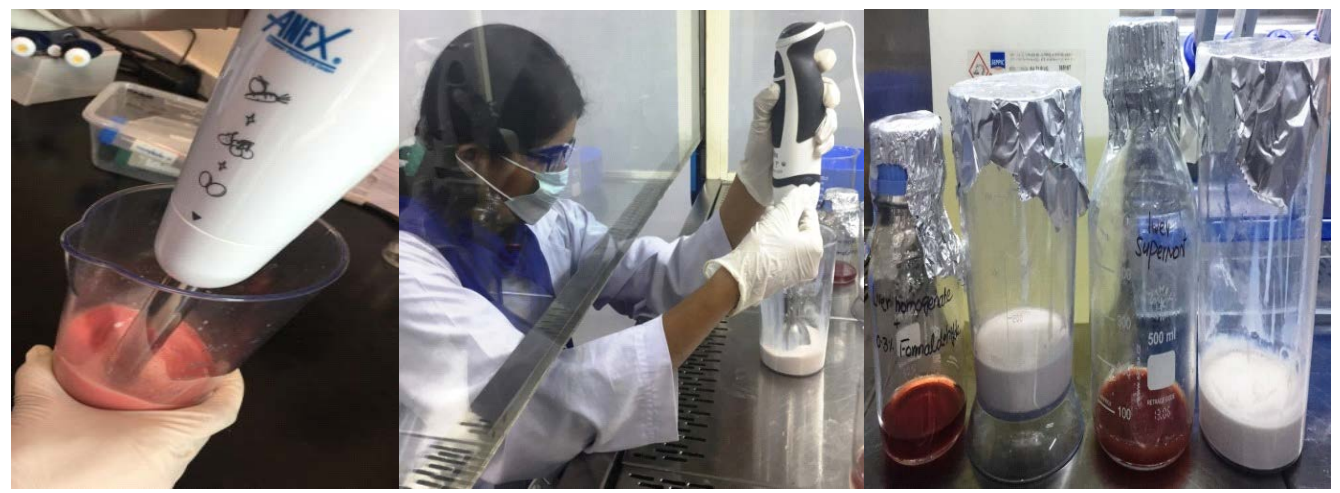

Figure 2. Vaccine preparation. 
in order to get 20 doses per gram, 25 doses per gram, 30 doses per gram of HPS virus infected liver homogenate vaccines containing $1 \times 10^{5.6}$ units of the $\mathrm{LD}_{50}$ respectively.

\subsubsection{Effect of Dose (Infectivity Titer)}

Ten grams of HPS virus infected liver homogenate containing $1 \times 10^{5.6}$ units of the $\mathrm{LD}_{50}$, in $60 \mathrm{ml}$ of sterilized normal saline was processed for preparation of HPS vaccines. The resulting solution was having immunogen amount; 20 doses per gram with $\mathrm{LD}_{50} 1 \times 10^{5.6}$ units of infectivity titer of virus. The resulting solution was having immunogen amount 20 doses per gram with $\mathrm{LD}_{50} 1 \times 10^{5.6}$ units of infectivity titer of virus. The resulting suspension having $\mathrm{LD}_{50}$ infectivity titer $1 \times 10^{5.6}$ was further diluted 10 and 100 times in order to obtain immunogen dose with $1 \times 10^{4.6}$ and $1 \times 10^{3.6}$ units of infectivity titer respectively.

$\mathrm{LD}_{50} 10^{5.6}:$ Dilution factor

$$
1: 10\left(\mathrm{LD}_{50} 10^{4.6}\right)
$$$$
1: 100\left(\mathrm{LD}_{50} 10^{3.6}\right)
$$

\subsection{Vero Cell Line Adapted HPS Virus Vaccines}

In vitro vero cell line was cultivated in DMEM media (Caisson-USA) with additional 5\% fetal calf serum (Gibco-UK) in T-175 disposable tissue culture flask as described previously by (Malik et al., 2018).

\subsection{HPS Virus Inoculation}

The confluent monolayer of vero cell line was inoculated with one ml of HPS virus inoculum $\left(1 \times 10 \mathrm{TCID}_{50}\right)$ and incubated at $37^{\circ} \mathrm{C}$ for 45 minutes. After viral adsorption, the infected vero cell line monolayer was supplemented with $8 \mathrm{ml}$ of DMEM containing $5 \%$ of FCS as maintenance media. One flask having confluent monolayer was kept as uninoculated/negative control. The monolayer was routinely observed for 3 - 5 days for appearance of any cytopathic effects (CPE) as compared with the normal cells in the control flask. When $90 \%$ of the infected cells were damaged due to $\mathrm{CPE}$, both the infected and control flasks were freeze-thawed thrice by alternately placed them at $-20^{\circ} \mathrm{C}$ in freezer and then at $25^{\circ} \mathrm{C}$ at room temperature.

The virus suspension was centrifuged at $500 \mathrm{~g}$ for 10 minutes and the cell free supernatant containing HPS virus was harvested. The harvest was stored at $-20^{\circ} \mathrm{C}$ in sterile media culture bottles. The HPSV suspension of disaggregated liver cells was processed for calculation of median tissue culture infective dose $\left(\mathrm{TCID}_{50}\right)$ (Figure 3) [10].

\subsection{Effect of Adjuvants}

Oil base montanide vaccine was prepared as directed by the manufacturer (SEPPIC-FRANCE). 30 parts of HPS infected liver suspension was homogenized with 70 parts of montanide ISA 70 MVG at $3000 \mathrm{rpm}$ for 10 minutes. 


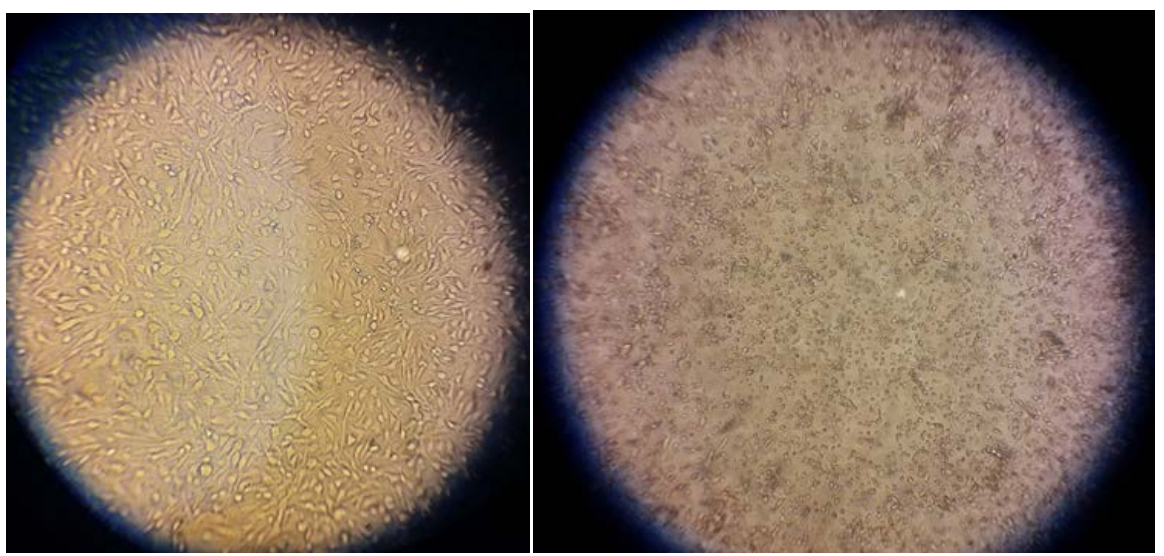

Figure 3. Healthy and HPSV infected vero cell line.

Aluminium hydroxide gel adjuvanted HPS vaccine was prepared by homogenizing 4 parts in 100 parts of HPS infected liver homogenate vaccine. Thiomersal sodium (Ethyl mercurithio salicylic acid, sodium salt $97 \%-101 \%$ used at $1: 30,000 \mathrm{w} / \mathrm{v}$ ) was added in the vaccine.

\subsection{Experimental Design}

\section{Experiment 1}

160 broilers birds were divided in to 10 groups; G1, G2, G3, G4, G5, G6, G7, G8, G9, G10, G11, G12, G13, G14, G15 and G16 (each group comprising 10 birds). The birds in groups G1, G2, G3, G4, G5, G6, G7, G8, G9, G10, G11, G12, G13, G14 and G15 were vaccinated with HPS infected liver homogenate (HPSILV), HPS liver homogenate fractioned vaccine (Supernatant) HPSLHFV, HPS liver homogenate vaccine (Sediment) (HPSLHSV), HPS tissue culture based vaccine (HPSTCBV), HPS liver homogenate oil based vaccine (HPSILOBV), HPS liver homogenate gel based vaccine (HPSILGBV), Tissue culture adapted HPS oil based vaccine (HPSTCOBV) and Tissue culture adapted gel based vaccine (HPSTCAGBV) respectively. The birds in Group G15 were injected with commercial HPS vaccine (Borringer-Germany) subcutaneously at dose rate of $0.3 \mathrm{ml}$ given per bird (mid dorsum region of neck). While, birds of group G16 were kept as no vaccinated control. After 14 days the birds were injected with booster with same dose and route (Table 1, Figure 4).

\subsection{Blood Collection}

$3 \mathrm{ml}$ of blood from each of the 5 birds of every group was collected on 20 and 40 days of post vaccination in sterile syringes. The syringes containing blood were kept at slant position at room temperature for overnight to separate. The serum thus separated was stored at $-60^{\circ} \mathrm{C}$ till further use (Figure 5).

\subsection{ELISA (Enzyme Linked Immunosorbent Assay) Testing}

Indirect ELISA was performed on all serum samples in 96 well plates following the procedures as described by the manufacturer (BioChek ELISA-Germany). 
Table 1. Experimental design.

\begin{tabular}{|c|c|c|c|}
\hline Sr. No & Group $(n=10)$ & Marking & Vaccine type \\
\hline 1 & G1 & Head Blue & HPS infected liver homogenate vaccine (HPSILV) \\
\hline 2 & G2 & Head Black & HPS liver homogenate fractioned vaccine (Supernatant) HPSLHFV \\
\hline 3 & G3 & Head Red & HPS liver homogenate vaccine (Sediment) (HPSLHSV) \\
\hline 4 & G4 & Head Green & ${ }^{\star}$ HPS tissue culture based vaccine (HPSTCBV) \\
\hline 5 & G5 & Head Purple & 20 Doses \\
\hline 6 & G6 & Wing Purple & 25 Doses \\
\hline 7 & G7 & Head Yellow & 30 Doses \\
\hline 8 & G8 & Wing Yellow & $\operatorname{TCID}_{50}\left(1 \times 10^{5.6}\right)$ \\
\hline 9 & G9 & Head Orange & $\operatorname{TCID}_{50}\left(1 \times 10^{4.6}\right)$ \\
\hline 10 & G10 & Wing Orange & $\operatorname{TCID}_{50}\left(1 \times 10^{3.6}\right)$ \\
\hline 11 & G11 & Red Wings & HPS liver homogenate oil based vaccine (HPSILOBV) \\
\hline 12 & G12 & Green Wings & HPS liver homogenate gel based vaccine (HPSILGBV) \\
\hline 13 & G13 & Black Wings & Tissue culture adapted HPS oil based vaccine (HPSTCOBV) \\
\hline 14 & G14 & Blue Wings & Tissue culture adapted HPS gel based vaccine (HPSTCAGBV) \\
\hline 15 & G15 & Purple Wings & Positive Control Group (PCG) commercial vaccine \\
\hline 16 & G16 & No Marking & Negative Control Group (NCG) \\
\hline
\end{tabular}

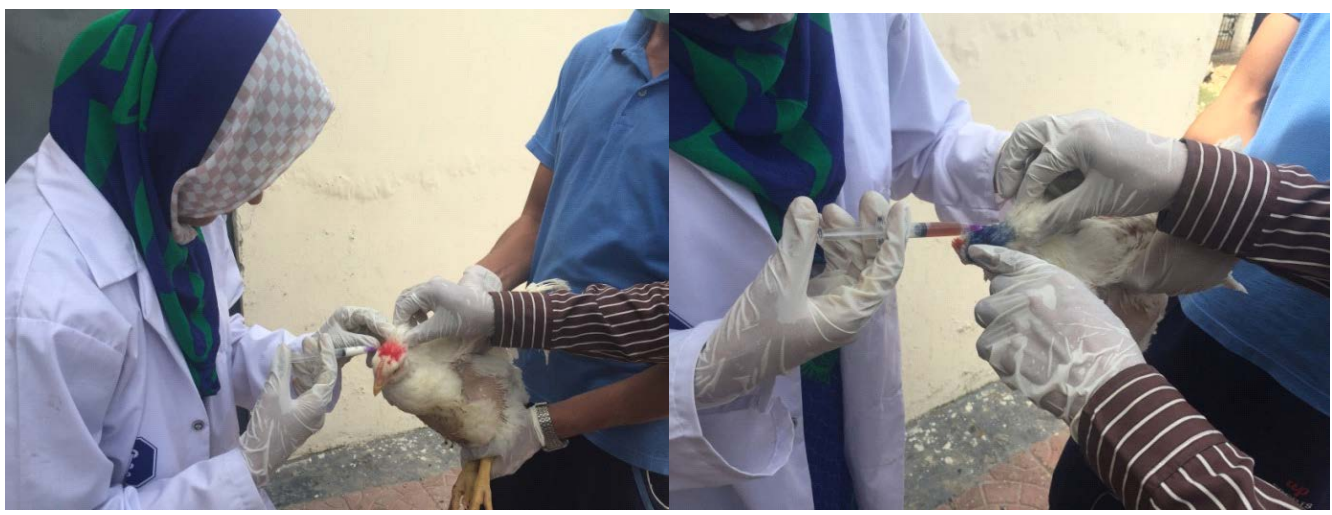

Figure 4. Vaccine inoculation.

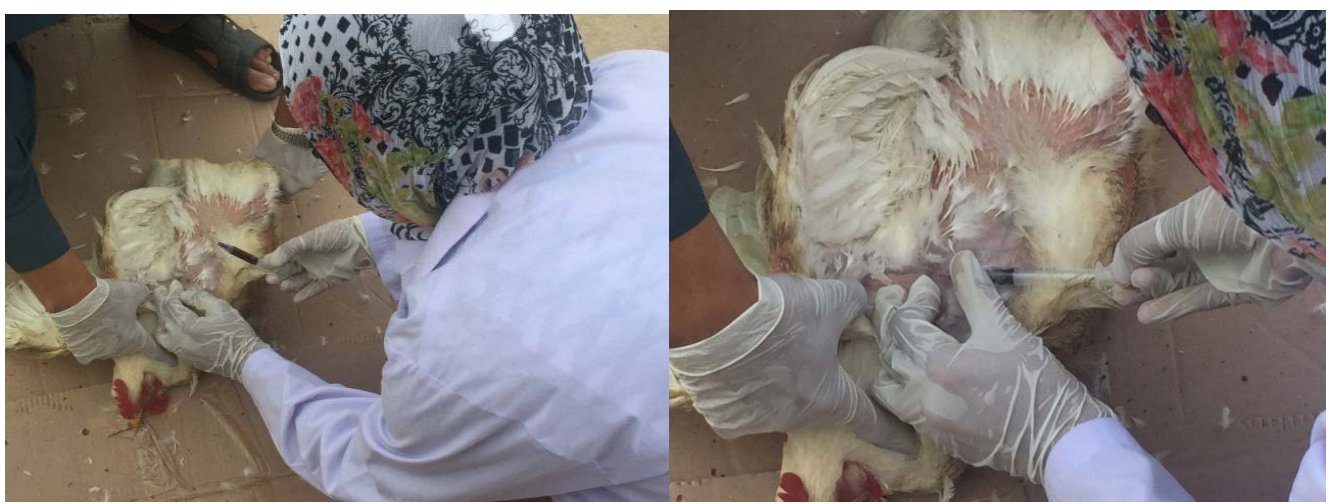

Figure 5. Blood collection. 


\subsubsection{Preparation of Samples}

All test samples were diluted five hundred folds (1:500) with sample diluents prior to assayed keeping controls as original by changing tips of the pipette every time. These samples were mixed thoroughly with the diluents and transferred to the coated plate.

\subsubsection{Test Procedure}

Reagents were allowed to settle at $18^{\circ} \mathrm{C}-26^{\circ} \mathrm{C}$, then mixed by inverting and swirling. The sample position on antigen-coated plate was recorded. $100 \mu \mathrm{l}$ of undiluted negative control and $100 \mu \mathrm{l}$ undiluted positive control was dispensed into duplicate wells. $100 \mu \mathrm{l}$ of diluted samples were also dispensed into appropriate marked wells. Fluid containing wells were incubated for $30 \mathrm{~min}$ at $18^{\circ} \mathrm{C}$ $26^{\circ} \mathrm{C}$. Each well of the plate was washed with approximately $250 \mu \mathrm{l}$ of distilled water 3 - 5 times and aspirated completely and $100 \mu \mathrm{l}$ of the conjugate was dispensed in each well and incubated for $30 \mathrm{~min}$ at $18^{\circ} \mathrm{C}-26^{\circ} \mathrm{C}$. Each well of the plate was washed with approximately $350 \mu \mathrm{l}$ of distilled water 3 - 5 times and aspirated completely and $100 \mu \mathrm{l}$ of TMB substrate solution was dispensed in each well and incubated for $15 \mathrm{~min}$ at $18^{\circ} \mathrm{C}-26^{\circ} \mathrm{C}$ followed by dispensing of $100 \mu \mathrm{l}$ each of the well to stop the reaction. Absorbance values were recorded at 650 nm, A (650) (Figure 6).

\subsection{Statistical Analysis}

The data on the challenge protection test were subjected to the statistical analysis for the interpretation of results by using one way analysis of variance.

\section{Results}

All Inactivated HPS virus oil based vaccines induced detectable anti-HPS ELISA antibody titers in HPS immunized 10 broilers on $20^{\text {th }}$ and $40^{\text {th }}$ day post vaccination. On $20^{\text {th }}$ day post vaccination HPS infected liver homogenate vaccine (HPSILV), HPS infected liver homogenate fractioned vaccine (Supernatant) (HPSLHFV), HPS infected liver homogenate fractioned vaccine (Sediment) (HPSLHSV), HPS tissue culture based vaccine (HPSTCBV), HPS infected liver positive control group (PCG) and negative control group (NCG) immunized

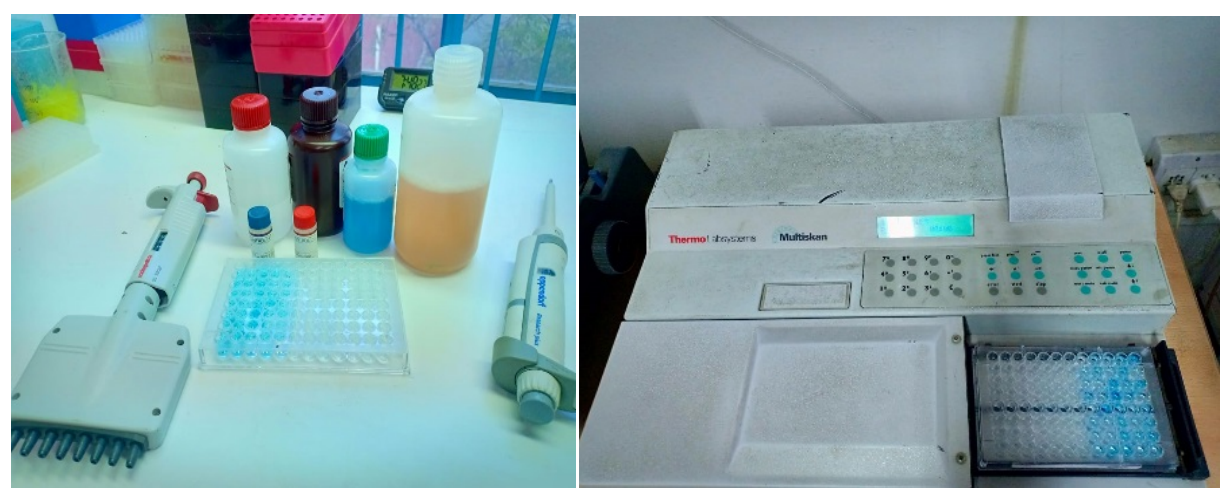

Figure 6. ELISA titration. 
broiler induced $1636.6 \pm 790.36,432.7 \pm 188.17,1134.1 \pm 127.33,1149.2 \pm$ 112.30, $1022.2 \pm 105.4$ and $32.2 \pm 19.73$ mean \pm standard deviation $(M \pm S D)$ of anti-HPS ELISA antibody titer respectively. Whereas, On $40^{\text {th }}$ day post vaccination HPS infected liver homogenate vaccine (HPSILV), HPS infected liver homogenate fractioned vaccine (Supernatant) (HPSLHFV), HPS infected liver homogenate fractioned vaccine (Sediment) (HPSLHSV), HPS tissue culture based vaccine (HPSTCBV), HPS infected liver positive control group (PCG) and negative control group (NCG) immunized broiler induced $2382.3 \pm 775.02$, $978.8 \pm 249.36,1255.1 \pm 89.71,1015.9 \pm 143.94,1170.4 \pm 85.86$ and $65.80 \pm 28.90$ $\mathrm{M} \pm \mathrm{SD}$ of anti-HPS ELISA antibody titer respectively (Table 2, Figure 7)

On $20^{\text {th }}$ day post vaccination HPS infected liver homogenate vaccine containing 20 doses, 25 doses and 30 doses per gram injected in broilers showed $1178.7 \pm$ $145.44,1059.1 \pm 101.66$ and $1037.3 \pm 101.79 \mathrm{M} \pm \mathrm{SD}$ of anti-HPS ELISA antibody

Table 2. Effect of source of vaccine on the base of Anti-HPS ELISA titer.

\begin{tabular}{|c|c|c|c|}
\hline No of vaccine & $\begin{array}{l}\text { Anti-HPS ELISA } \\
\text { antibody titer } 20^{\text {th }} \text { days }\end{array}$ & $\begin{array}{l}\text { Anti-HPS ELISA } \\
\text { antibody titer } 40^{\text {th }} \text { days }\end{array}$ & $\begin{array}{c}\text { Mean } \pm \text { Standard } \\
\text { deviation }\end{array}$ \\
\hline $\begin{array}{l}\text { HPS infected liver homogenate } \\
\text { (HPSILV) }\end{array}$ & $\begin{array}{c}692,2456,2678,1176,1578,1248,563,2348 \\
1146,2478=1636.6 \pm 790.36\end{array}$ & $\begin{array}{c}1248,3156,3245,1784,2057,2348,1284 \\
3078,2456,3167=2382.3 \pm 775.02\end{array}$ & $2009.3 \pm 852.56$ \\
\hline $\begin{array}{l}\text { HPS liver homogenate fractioned } \\
\text { Vaccine (supernatant) (HPSLHFV) }\end{array}$ & $\begin{array}{c}456,115,596,494,598,496,120,450,656 \\
346=432.7 \pm 188.17\end{array}$ & $\begin{array}{c}1016,356,1098,1096,1105,969,1017 \\
1087,1256,788=978.8 \pm 249.36\end{array}$ & $705.75 \pm 353.14$ \\
\hline $\begin{array}{l}\text { HPS liver homogenate vaccine } \\
\text { (sediment) (HPSLHSV) }\end{array}$ & $\begin{array}{c}954,1074,967,1145,1340,1212,1098,1156 \\
1306,1089=1134.1 \pm 127.33\end{array}$ & $\begin{array}{c}1198,1204,1138,1281,1204,1318,1206 \\
1378,1416,1208=1255.1 \pm 89.71\end{array}$ & $1194.6 \pm 123.87$ \\
\hline $\begin{array}{c}{ }^{\star} \text { HPS tissue culture based vaccine } \\
\text { (HPSTCBV) }\end{array}$ & $\begin{array}{c}1204,984,1014,1184,1234,1138,98,1254 \\
1237,1256=1149.2 \pm 112.30\end{array}$ & $\begin{array}{c}1254,1065,1104,998,945,834,806,903 \\
1142,1108=1015.9 \pm 143.94\end{array}$ & $1082.55 \pm 143.05$ \\
\hline $\begin{array}{l}\text { Positive Control Group } \\
\text { (PCG) }\end{array}$ & $\begin{array}{c}1104,998,1054,924,1017,1071,893,1243 \\
1015,90=1022.2 \pm 105.43\end{array}$ & $\begin{array}{c}1285,1104,1184,1087,1085,1218,1285 \\
1043,1198,1215=1170.4 \pm 85.86\end{array}$ & $1096 \pm 120.57$ \\
\hline $\begin{array}{l}\text { Negative Control Group } \\
\qquad(\mathrm{NCG})\end{array}$ & $\begin{array}{c}34,24,42,34,43,12,32,2,24,75 \\
=32.2 \pm 19.73\end{array}$ & $\begin{array}{c}56,43,78,98,98,34,74,24,48,105 \\
=65.8 \pm 28.99\end{array}$ & $49 \pm 29.61$ \\
\hline
\end{tabular}

Primary culture of 12-day old chicken embryo hepatocytes.

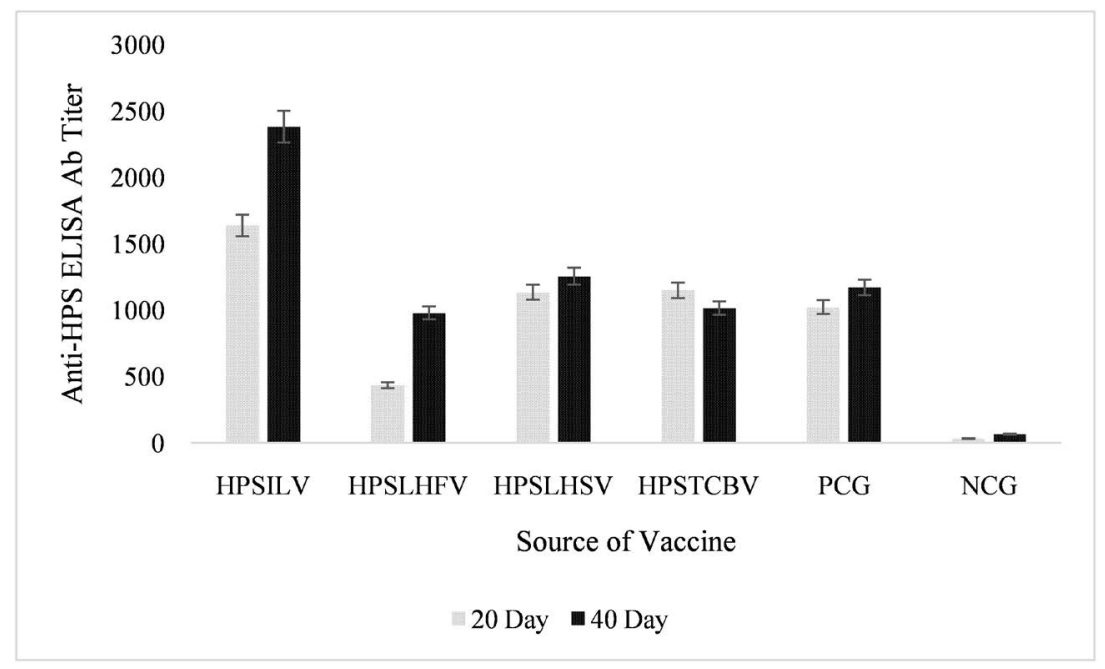

Figure 7. Effect of source of vaccine to Anti-HPS ELISA antibody titer. 
titer as compare to $40^{\text {th }}$ day post vaccination $1042.1 \pm 65.77,1084.7 \pm 94.48$ and $1038.4 \pm 91.24$ respectively. Moreover, on $20^{\text {th }}$ day post vaccination vero cell line adapted HPS virus vaccine containing immunogenic level of $1 \times 10^{5.6}, 1 \times 10^{4.6}, 1$ $\times 10^{3.6}$, Positive control group (PCG) and Negative control group (NCG) injected in broilers showed $1127.7 \pm 67.68,977.9 \pm 41.51,816.4 \pm 80.62,1022.2 \pm$ 105.4 and $32.2 \pm 19.73 \mathrm{M} \pm \mathrm{SD}$ of anti-HPS ELISA antibody titer as compare to $40^{\text {th }}$ day post vaccination $1052.5 \pm 18.04,772.6 \pm 133.1,588.00 \pm 61.97,1170.4 \pm$ 85.86 and $65.80 \pm 28.90$ respectively (Table 3, Figure 8, Figure 9).

Adjuvants play a vital role in the stimulation and augmentation of immune response but chiefly act as depot effect at injection site. On $20^{\text {th }}$ day post vaccination

Table 3. Effect of immunogen count on the efficacy of HPS vaccine.

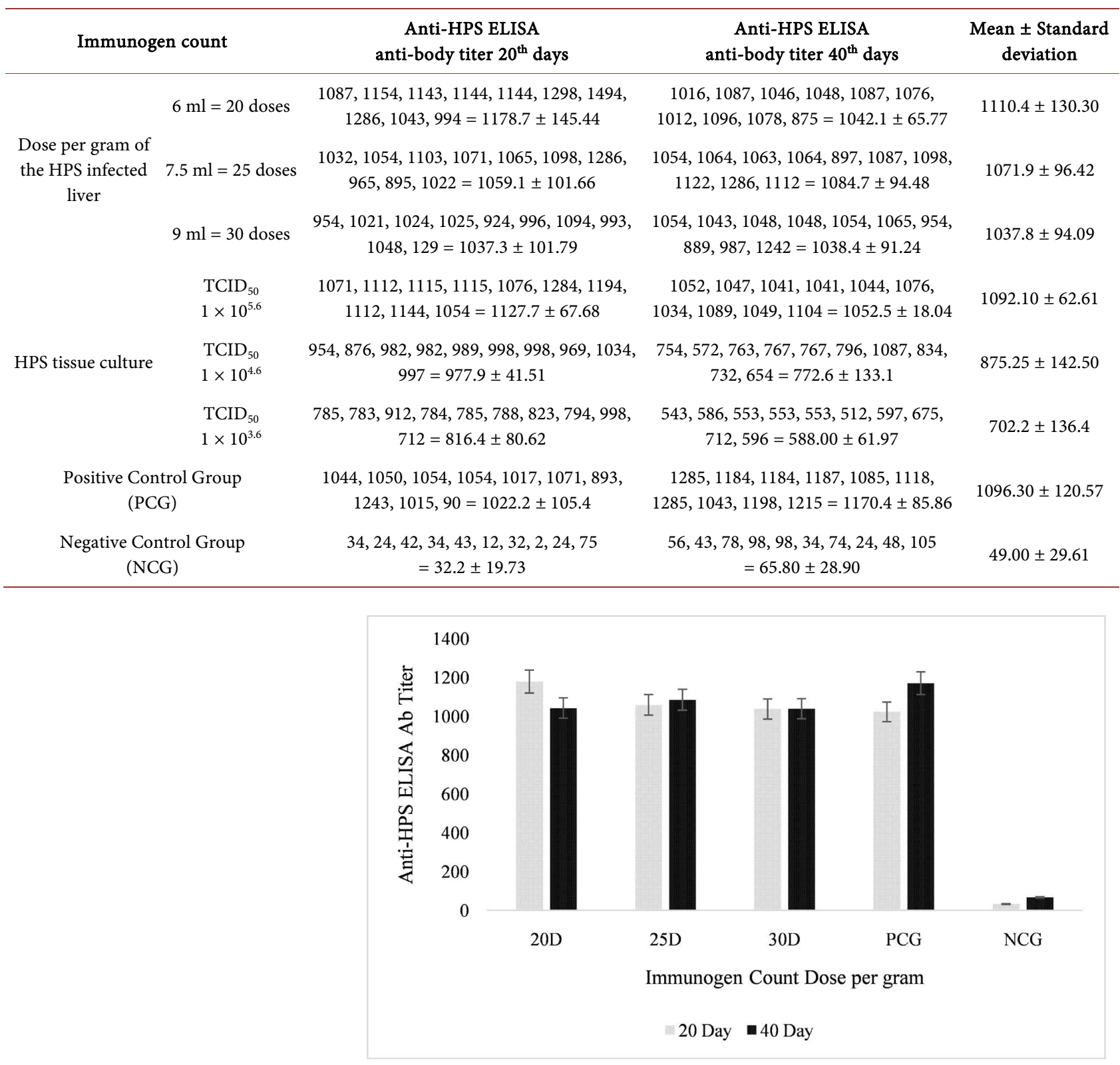

Figure 8. Effect of dose per gram immunogen count on the efficacy of HPS vaccine. 
HPS liver homogenate oil based vaccine (HPSILOBV), HPS liver homogenate gel based vaccine (HPSILGBV), Tissue culture adapted HPS oil based vaccine (HPSTCOBV), Tissue culture adapted gel based vaccine (HPSTCAGBV), Positive control group (PCG) and Negative control group (NCG) injected in broiler birds induced $1003.4 \pm 68.27,1033 \pm 141.73,1041.7 \pm 42.65,1214.2 \pm 275.02$, $1022.2 \pm 105.4$ and $32.2 \pm 19.73 \mathrm{M} \pm \mathrm{SD}$ of anti-HPS ELISA antibody titer respectively. Furthermore, On $40^{\text {th }}$ day post vaccination HPS liver homogenate oil based vaccine (HPSILOBV), HPS liver homogenate gel based vaccine (HPSILGBV), Tissue culture adapted HPS oil based vaccine (HPSTCOBV), Tissue culture adapted gel based vaccine (HPSTCAGBV), Positive control group (PCG) and Negative control group (NCG) injected in broiler birds induced $1216.5 \pm 110.82$, $1026 \pm 109.27,1255.2 \pm 156.7,1060.2 \pm 35.93,1170.4 \pm 85.86$ and $65.80 \pm$ $28.90 \mathrm{M} \pm \mathrm{SD}$ of anti-HPS ELISA antibody titer respectively (Table 4, Figure $10)$.

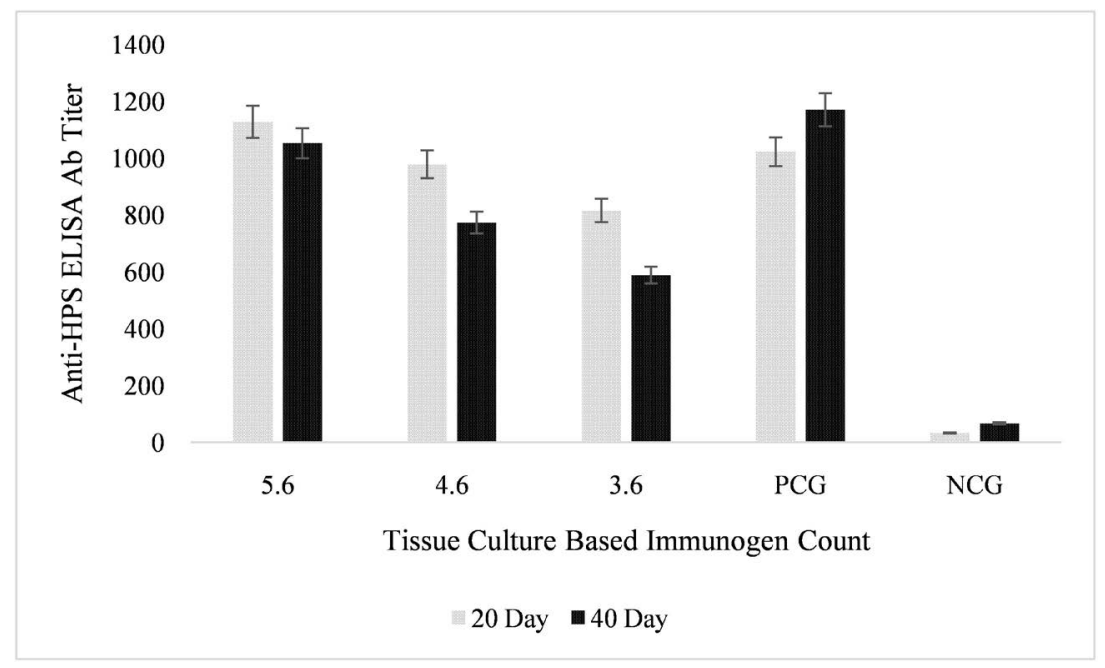

Figure 9. Effect of tissue culture based immunogen count on the efficacy of HPS vaccine.

Table 4. Effect of Adjuvant on the efficacy of HPS infected liver homogenate vaccine.

\begin{tabular}{|c|c|c|c|}
\hline Adjuvant & $\begin{array}{l}\text { Anti-HPS ELISA } \\
\text { anti-body titer } 20^{\text {th }} \text { days }\end{array}$ & $\begin{array}{l}\text { Anti-HPS ELISA } \\
\text { anti-body titer } 40^{\text {th }} \text { days }\end{array}$ & $\begin{array}{l}\text { Mean } \pm \text { Standard } \\
\text { deviation }\end{array}$ \\
\hline $\begin{array}{l}\text { HPS liver homogenate oil based } \\
\text { vaccine (HPSILOBV) }\end{array}$ & $\begin{array}{c}945,984,1071,1071,1073,1037,892 \\
1051,912,998=1003.4 \pm 68.27\end{array}$ & $\begin{array}{c}1078,1184,1184,1183,1084,1198,1174 \\
1298,1370,1412=1216.5 \pm 110.82\end{array}$ & $1109.95 \pm 141.34$ \\
\hline $\begin{array}{l}\text { HPS liver homogenate gel based } \\
\text { vaccine (HPSILGBV) }\end{array}$ & $\begin{array}{c}970,976,945,945,945,1013,865,1143 \\
1289,1243=1033 \pm 141.73\end{array}$ & $\begin{array}{c}987,998,984,998,984,998,991,879,1221 \\
1224=1026 \pm 109.27\end{array}$ & $1029.9 \pm 123.22$ \\
\hline $\begin{array}{l}\text { Tissue culture adapted HPS oil } \\
\text { based vaccine (HPSTCOBV) }\end{array}$ & $\begin{array}{c}1074,1045,1067,1004,938,1076,1054 \\
1036,1075,1048=1041.7 \pm 42.65\end{array}$ & $\begin{array}{c}1178,1221,1221,1221,1099,1541,1465 \\
1306,1286,1014=1255.2 \pm 156.7\end{array}$ & $1148.45 \pm 156.53$ \\
\hline $\begin{array}{l}\text { Tissue culture adapted gel based } \\
\text { vaccine (HPSTCAGBV) }\end{array}$ & $\begin{array}{c}1175,1098,1094,1096,1074,1186,1983, \\
1090,1232,1114=1214.2 \pm 275.02\end{array}$ & $\begin{array}{l}1017,1054,1054,1055,1014,1097,1103 \\
1112,1074,1022=1060.2 \pm 35.93\end{array}$ & $1137.2 \pm 206.59$ \\
\hline $\begin{array}{l}\text { Positive Control Group } \\
\text { (PCG) }\end{array}$ & $\begin{array}{c}1044,1050,1054,1054,1017,1071,893 \\
1243,1015,90=1022.2 \pm 105.4\end{array}$ & $\begin{array}{c}1285,1184,1184,1187,1085,1118,1285 \\
1043,1198,1215=1170.4 \pm 85.86\end{array}$ & $1096.30 \pm 120.57$ \\
\hline $\begin{array}{l}\text { Negative Control Group } \\
\text { (NCG) }\end{array}$ & $\begin{array}{c}34,24,42,34,43,12,32,2,24,75 \\
=32.2 \pm 19.73\end{array}$ & $\begin{array}{c}56,43,78,98,98,34,74,24,48,105 \\
=65.80 \pm 28.90\end{array}$ & $49.00 \pm 29.61$ \\
\hline
\end{tabular}




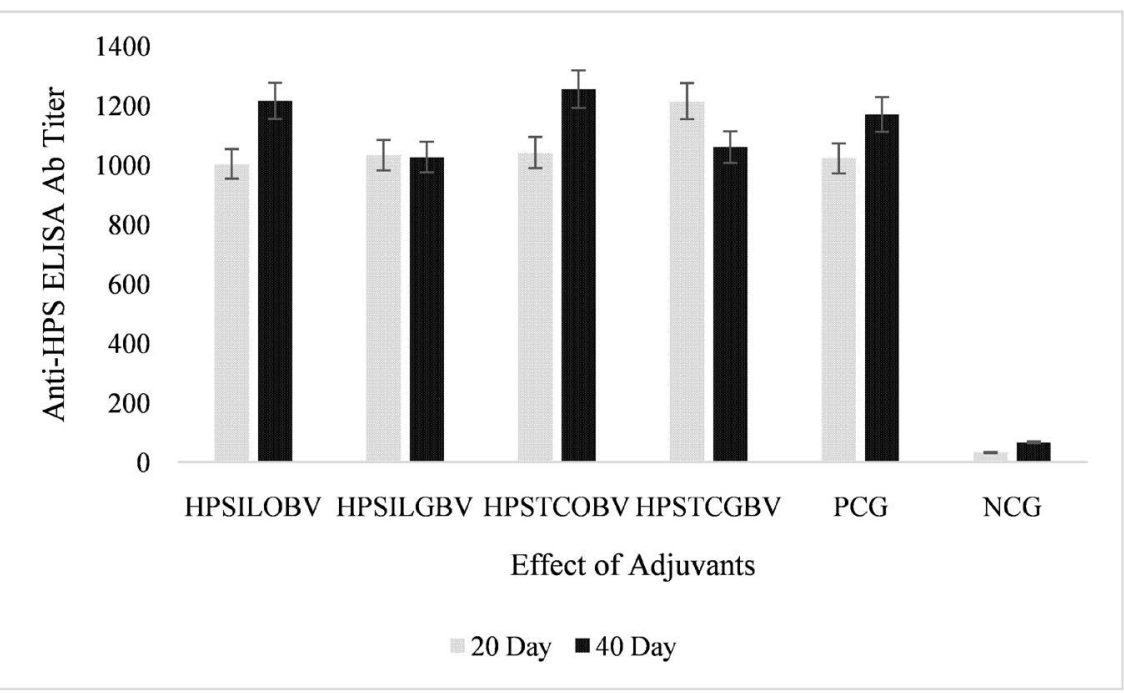

Figure 10. Effect of adjuvant on the efficacy of HPS infected liver homogenate vaccine.

\section{Discussion}

HPS infected liver obtained from Ottoman Pharma (Immuno Division) was reactivated in 26 days old healthy birds. The HPS infected liver homogenate (AOW/V\%) was injected through I/M route for the production of disease. At postmortem showed fragile liver with white striations on capsule along with clear straw color fluid in the pericardial sac of heart as showed in Figure 1. These findings are similar in observation of [11].

Different vaccines were prepared on the basis of immunogen count, infectivity titer of virus, source of antigen and role of adjuvants. All the vaccines are injected to day old healthy chicken broilers. 25 doses/gm vaccines showed significantly higher anti-HPS ELISA antibody titer on $42^{\text {th }}$ days post vaccination as compare to vaccine prepared from higher dilutions. Infectivity titers play an important role in the stimulation of earlier humoral response. The vaccine having infectivity titer of $1 \times 10^{5.6} / \mathrm{ml} \mathrm{BLD}_{50}$ showed better humoral response in terms of anti-HPS ELISA antibody titer to that of higher dilutions such as $1 \times$ $10^{4.6} / \mathrm{ml} \mathrm{BLD}_{50}$ and $1 \times 10^{3.6} / \mathrm{ml} \mathrm{BLD}_{50}$.

According to current study HPS infected liver homogenate is the most appropriate material for the production of efficacious vaccine which have the ability to induce protective antibody titer in shorter period of time. The HPS infected liver homogenate vaccine induced higher anti-HPS ELISA antibody titer to that of primary culture of chicken embryo hepatocytes based HPS vaccine. The reason may be biological titer induced during infection under biological system in natural host where it gets replicative momentum and ultimately results into higher antigen count responsible for the production of higher antibody even injected with minimal volume of dose. This could be the possible reason for its significant humoral response.

Formalin-inactivated liver organ vaccines are the only available source of vaccines against HPS in Pakistan, which have been unable to control/eradicate dis- 
ease. Liver homogenate vaccine showed significantly higher serum anti-HPS ELISA antibody titer $(2009.3)$ on $40^{\text {th }}$ days post vaccination as compare to HPS liver homogenate fractioned vaccine (Supernatant) 705.75, HPS liver homogenate vaccine (Sediment) 1194.6 and HPS tissue culture based vaccine 1096. The results of current study are well supported by [12] who reported that HPS liver homogenate vaccine is better source of adenovirus cultivation particularly for vaccine production. Since avian adenovirus belongs to genus adenovirus and family aviadenovirdiae. Therefore, birds are the natural host for these viruses where they replication well in natural supportive environment and produce remarkable titer.

Effect of immunogen count as 20 doses per gram of the HPS infected liver based vaccine showed significantly higher serum anti-HPS ELIS A antibody titer (1110.4) on $40^{\text {th }}$ days post vaccination as compare to 25 doses (1071.9) and 30 doses. Mehmood reported that the vaccine containing 20, 25, 30, 35 and 45 doses as an immunogen without gel induced higher immunity and such birds therefore, showed 100, 90, 90, 50 and 20 percent resistance respectively [13]. While, vaccines with gel containing $20,25,30,35$ and 45 doses that induced immunity $100,100,100,70$ and 30 protection to challenge infection respectively. This is somewhat in line with Ahmad, Mashkoor and Noor-ul-Hassan who recorded difference in protection percentage of birds vaccinated with $1 \%, 2.5 \%, 5 \%, 7.5 \%$ and $10 \%$ liver organ vaccines [14] [15] [16]. Therefore, it was concluded that the gel based vaccines provide better protection as compared to vaccine without gel.

Adjuvants play a critical role in the augmentation of immune response. Tissue culture adapted HPS oil based vaccine (1148.45) showed slightly better serum anti-HPS ELISA antibody titer on $40^{\text {th }}$ days post vaccination as compare to tissue culture adapted gel based vaccine (1137.2), HPS liver homogenate oil based vaccine (1109.95) and HPS liver homogenate gel based vaccine (1029.9). The results of current study are well supported by Sahidullah who reported that oil based adjuvanted vaccines confers good, long-lasting protection against HPS field virus challenge [17]. Mehmood reported that the protection titer in vaccinated birds was found to be the highest for montanide based HPS virus vaccine (100\%), followed by aluminum hydroxide gel based vaccine $(80 \%)$, whereas the vaccine without adjuvant provided $40 \%$ protection when challenged with virulent virus at 28 days post vaccination [13]. These findings are congruent with the observations of Hussain and Roy [7] [18]. The variation in the protection percentage induced by montanide and lanolin based vaccine could be due to instability of the latter during storage.

The results of the current study revealed infected liver homogenate vaccine induced significantly higher anti-HPS ELISA antibody titer (2009.3) to that of primary culture of liver hepatocytes adapted virus vaccine (1082.5) regardless of its composition due to production of heavy antigenic count per volume is well supported by substrate and the environment. The findings are in line with Jabeen who reported that in his study that efficacy of liver culture based inacti- 
vated adjuvanted vaccines was significantly higher at 2 week post vaccination ( $\mathrm{P}$ $<0.05)$ than groups tissue homogenate based inactivated vaccines [19].

During earlier days of investigation many attempts were made for the control of HPS in broilers by using formalin inactivated liver homogenate vaccines and there have been a lot of contrary findings regarding the efficacy of such liver homogenate vaccines. The results of the present study suggested that tissue culture based inactivated vaccines performed best in experimental conditions as compared to liver homogenate vaccine. Our results are in close agreement with already reported work.

The objective of the present study was to develop cell culture based efficacious vaccine against HPS in poultry. Cell culture based inactivated montanide adjuvanted vaccine performed better in experimental conditions and showed protective anti-HPS ELISA antibody titers whereas, HPS infected liver homogenate based technology could be considered as better tool for the production of inactivated vaccines. However, it is recommended that further trials may be designed to get fully adapted aviadenovirus with optimum growth in limited time which shall replace commercial tissue homogenate based vaccine.

\section{Conclusion}

It is observed that the HPS vaccine containing more than $10^{5.6}$ units of immunogen is effective for broilers to achieve the required level of resistance to field challenge. Less than 20 doses per gram of the HPS infected liver homogenate containing $10^{5.6}$ units of immunogen can be prepared for effective immuno-prophylaxis. Addition of the oil base montanide in the HPS infected liver homogenate vaccine improves its efficacy and induces immunity for longer period of time.

\section{Recommendations}

- HPS liver homogenate vaccine shall contain more than $10^{4.6}$ units of immunogen for broilers as compare to tissue cultured HPS vaccine where minimum immunogen count would be $10^{5.6}$.

- Always prepare 20 doses per gram from HPS infected liver having $10^{5.6} \mathrm{BLD}_{50}$.

- Montanide oil can be better alternative adjuvant for breeders and layers which can induces immunity for longer period of time.

- Tissue culture adopted fowl adeno virus vaccine is free of non-specific liver cells and other extraneous agents. Hence, could be used for effective immuno prophylaxis without any ill effect.

\section{Conflicts of Interest}

The authors declare no conflicts of interest regarding the publication of this paper.

\section{References}

[1] Anonymous (1988) Synopsis on the Proceedings of 1st National Seminar on the 
Hydro-Pericardium Syndrome Agent. In: Proceedings 2nd Seminar on Hydro-Pericardium Syndrome, PRI, Rawalpindi, 111-115.

[2] Chishti, M.A., Afzal, M. and Cheema, A.H. (1898) Preliminary Studies on the Development of Vaccine against the Hydro-Pericardium Syndrome of Poultry. Revue Scientifique et Technique, 8, 797-801. https://doi.org/10.20506/rst.8.3.432

[3] Rabbani, M., Muneer, A. and Naeem, K. (1989) Development of Heterotypic Vaccine against Angara Disease Associated Avian Adenovirus. Pak J Livestock Res, 8, 104-112.

[4] Ahmad, I., Afzal, M., Malik, M.I., Hussain, Z. and Hanif, W. (1989) Disease Pattern and Etiology of Hydro-Pericardium Syndrome (Angara Disease) in Broiler Chicken in Pakistan. Pakistan Journal of Agricultural Research, 10, 195-199.

[5] Dahiya, S., Srivastava, R.N., Hess, M. and Gulati, B.R. (2002) Fowl Adenovirus Serotype 4 Associated with Outbreaks of Infectious Hydro-Pericardium in Haryana. Avian Diseases, 46, 230-233. https://doi.org/10.1637/0005-2086(2002)046[0230:FASAWO]2.0.CO;2

[6] Anjum, A.D., Sabri, M.A. and Iqbal, Z. (1989) Hydro-Pericardium Syndrome in Broiler Chicken in Pakistan. Veterinary Record, 124, 247-248.

https://doi.org/10.1136/vr.124.10.247

[7] Husnain, I., Munir, R., Akhtar, M. and Ahmad, R. (1999) Evaluation and Comparison of Hydro-Pericardium Syndrome Vaccines in Broiler Chicks. Pakistan Veterinary Journal, 19, 88-90.

[8] Khan, A.A., Sabri, A.B., Mansoor, M.K. and Hussain, I. (2005) Hydro-Pericardium Syndrome in Pakistan: A Review. World s Poultry Science Journal, 8, 647-654. https://doi.org/10.1079/WPS200576

[9] Rabbani, M. (1997) Observation and Causative Agent of Hydro-Pericardium Syndrome in Chickens. Ph.D. Thesis, Microbiology Section (CVS Lahore), Univ. Agric., Faisalabad.

[10] Reed, L.J. and Muench, M. (1938) A Simple Method for Estimating Fifty Percent End Point. American Journal of Hygiene, 27, 493-497. https://doi.org/10.1093/oxfordjournals.aje.a118408

[11] Khawaja, D.A., Ahmad, S., Rouf, M., Zulfiqar, M. and Mehmood, S.M.I. (1988) Isolation of an Adeno Virus from Hydro-Pericardium Syndrome in Broiler Chicks. PakJ Vet Res, 1, 2-17.

[12] Adair, B.M. and Fitzgerald, S.D. (2008) Group I Adenovirus Infections. In: Saif, Y.M., Fadly, A.M., Glisson, J.R., McDougald, L.R., Nolan, L.K. and Swayne, D.E., Eds., Disease of Poultry, 12th Edition, Blackwell Publishing, Iowa, 252-266.

[13] Mehmood, M.D., Muhammad, K., Rabbani, M., Hanif, A. and Hussain, I. (2011) In Process Quality Control Factors Affecting the Efficacy of Hydro-Pericardium Syndrome Virus Vaccine. Pakistan Journal of Zoology, 43, 73-77.

[14] Ahmad, M.D. (1994) Studies on Avian Adenoviruses (Group-1) Associated with Inclusion Body Hepatitis. Ph.D. Thesis, Department of Biomedical and Tropical Veterinary Science, James Cook University of North Queensland, North Queensland.

[15] Mashkoor, S., Hameed, A., Ahmad, K. and Qureshi, M.S. (1994) Immune Response of Angara Disease (Hydro-Pericardium Syndrome) Vaccines in Broilers. Veterinarski Arhiv, 64, 103-107.

[16] Noor-ul-Hassan, Afzal, M., Hameed, A. and Khan, R.A.R. (1994) Immune Response to Inactivated Hydro-Pericardium Syndrome Vaccines in Broilers. Pakistan Veterinary Journal, 14, 5-10. 
[17] Sahidullah, Sadeeq-ur-rahman, Rabbani, M., Shah, M.K., Naseem, S. and Khan, S.H. (2008) Development of Standard Protocols for Preparation and Evaluation of Liver Homogenate Vaccines against Hydro-Pericardium Syndrome Virus in Poultry. Pakistan Veterinary Journal, 28, 163-166.

[18] Roy, P., Koteeswaram, A. and Manickam, R. (1999) Efficacy of an Inactivated Oil Emulsion Vaccine against Hydro-Pricardium Syndrome in Broilers. Veterinary Record, 145, 458-459. https://doi.org/10.1136/vr.145.16.458

[19] Jabeen, A., Naeem, K., Siddique, N. and Naqvi, S.M.S. (2015) Cloning, Sequencing and Bioinformatic Analysis of Hypervariable Region of Hexon Gene of Avian Adenovirus 4 (AAV4) Associated with Angara Disease from Pakistan. International Journal of Agriculture and Biology, 17, 833-837.

https://doi.org/10.17957/IJAB/14.0014 